\title{
Mortality of United Kingdom acrylonitrile polymerisation workers
}

\author{
J B WERNER ${ }^{1}$ AND J T CARTER ${ }^{2}$
}

From the Health and Safety Executive, ${ }^{1}$ London W2 4TF, and BP Chemicals Ltd, ${ }^{2}$ London SW1W $05 U$ (on behalf of the Chemical Industries Association)

ABSTRACT The mortality of 1111 men who worked on the polymerisation of acrylonitrile and the spinning of acrylic fibre from 1950 to 1968 was surveyed up to the end of 1978. Seventy-nine deaths were identified. The population was drawn from six factories, where polymerisation started before 1968 , in England, Wales, Scotland, and Northern Ireland. In the group of men exposed to acrylonitrile for at least one year the total number of deaths was smaller than expected. An excess of deaths from all cancers was found, arising mainly from cancers of the lung, stomach, colon, and brain, but the excess was not statistically significant. Significant excesses of stomach cancer overall and in those aged 55-64, and of lung cancer in those aged 15-44 were found. Consideration of deaths according to factory indicated that the excesses of stomach cancer may have been due to regional factors. The excess of lung cancer was investigated further in view of the fact that, unusually, it occurred in relatively young men, but no consistent difference between the duration of exposure to acrylonitrile of the three young patients with lung cancer and matched controls was found. The study is limited and further analysis in the future is needed. The results are not conclusive and neither add to nor detract from existing suspicions that acrylonitrile is a human carcinogen but, taken together with evidence from other studies, indicate the necessity for the continuing surveillance of the exposed population in the United Kingdom.

Suggestions that acrylonitrile may have a carcinogenic effect in man come from an epidemiological study ${ }^{1}$ carried out in the United States and from two series of animal experiments. ${ }^{2} 3$ The latter showed a carcinogenic effect in rats and particularly noted the induction of brain tumours.

The epidemiological study covered workers in a single Du Pont plant in the United States: mortality and cancer registration data for men exposed to acrylonitrile were analysed. A comparison of the number of cancer registrations with the numbers that would have been expected if the rates experienced throughout the Du Pont company in the United States had applied, led the author to conclude that men exposed to acrylonitrile suffered an excess risk of cancer, in particular of lung cancer. The study, however, did not show a significant excess of deaths from cancer or lung cancer. Other epidemiological studies $^{4}$ (and Association of Dutch Chemical

Received 8 September 1980

Accepted 6 October 1980
Industry and Monsanto Company, unpublished reports) carried out in Europe and the United States have not reached firm conclusions about the effects of acrylonitrile exposure in man. The study 5 in the BASF company reported an excess of deaths from lung cancer, but this was largely due to an excess in one plant. In addition two cases of Hodgkin's disease contributed to a slight excess of cancer of the lymphatic tissue. However, the numerous mixed exposures, partly to known carcinogens, made interpretation of the results difficult.

The present study was set up in 1978, after consultation between the Health and Safety Executive and the Chemical Industries Association, to investigate whether a carcinogenic risk existed for workers exposed to acrylonitrile in the United Kingdom.

\section{Methods}

STUDY POPULATION

Details were collected of 1111 men in six factories in the United Kingdom who worked on the polymerisa- 
tion of acrylonitrile and the spinning of acrylic fibre at any time during the period between 1950 , when production started in one of the factories, and 1968. All the major sites where acrylonitrile was polymerised in 1968 or earlier were included (England (2), Wales (2), Scotland (1), and Northern Ireland (1)). The population was initially defined to include only men who had worked on the polymerisation process itself, because this is where the highest exposures were known to have occurred. In one plant, however, men working as spinners in an area where exposures had been equally high were also included. The condition that exposure should have occurred in 1968 or earlier was imposed so that potentially at least ten years of follow-up was possible for every man.

Returns giving identification details were made by each factory on survey cards supplied by HSE, and these were sent for tracing and flagging to whichever of the following national offices was appropriate: in England and Wales, the National Health Service Central Register (NHSCR) maintained by the Office of Population Censuses and Surveys (OPCS); Scotland, the NHSCR maintained by the General Register Office for Scotland (GRO(S)); and Northern Ireland, the Central Services Agency. No record could be found for 18 of the men, but 16 of these were subsequently traced on the National Insurance Register maintained by DHSS.

For the remaining two men who could not be traced, information on status was available only up to the date of leaving the company. Similarly, for 20 men who emigrated during the follow-up period information was available only up to the date of emigration. The dates of leaving and dates of emigration were obtained from the companies and from the NHSCR respectively. For the rest of the population records giving the dates of all deaths occurring during the period up to 31 December 1978 were obtained (with the underlying cause of death coded to the 8th Revision of the International Classification of Diseases) from OPCS, GRO(S), or the General Register Office for Northern Ireland.

For each man in the study population a set of survey cards was completed giving the dates of starting and finishing each job in the factory after first exposure to acrylonitrile. These details were used to separate the 177 men with less than one year's exposure from the 934 with exposure lasting one year or more. The division at one year was chosen because this is a convenient lower limit for the duration of exposure that is often adopted in surveys of this type to identify a population about which any conclusions associating the effects of exposure with the observed mortality pattern can be justified. No further division of the whole population by duration of exposure was made since insufficient numbers of deaths had occurred to make this valuable, but the durations of exposure of three men who died of lung cancer at relatively young ages were compared with the exposures of matched controls.

CALCULATION OF MAN-YEARS AT RISK AND EXPECTED NUMBERS OF DEATHS

The period at risk for the category exposed for under one year was taken to be the total period from the date of first exposure for each man with under one year's exposure, plus the first year after the date of first exposure for each man with at least one year's exposure. The period at risk for the one year or more exposure category was taken to be the total period from the date exactly one year after first exposure for each man with at least one year's exposure. The period at risk was calculated to the nearest day for each man up to the date of emigration, date of death, or 31 December 1978, according to which was earliest. For the two men who could not be traced, the period at risk was calculated up to the date of leaving the company. Man-years at risk were calculated in fiveyear age bands for each of the years 1950-78 covered by the study. Table 1 shows the total man-years at risk for the study population giving a division by age and year of first exposure. The groups shown were defined so far as possible to produce five-year bands, or aggregates of these, and the results are presented using the same categories. Table 1 also shows the number of men in each exposure group.

Expected numbers of deaths were calculated by applying standard age specific mortality rates for the

Table 1 Population size and man-years at risk by age and cohort

\begin{tabular}{|c|c|c|c|c|c|c|}
\hline & \multirow[t]{2}{*}{ No of men } & \multicolumn{5}{|c|}{ Man-years at risk by age group } \\
\hline & & $15-44$ & $45-54$ & $55-64$ & $\geqslant 65$ & Total \\
\hline \multicolumn{7}{|l|}{ Men exposed for one year or more: } \\
\hline First exposed during $\mathbf{1 9 5 0 - 8}$ & 158 & $1503 \cdot 5$ & $958 \cdot 0$ & $594 \cdot 5$ & $185 \cdot 1$ & $3241 \cdot 1$ \\
\hline First exposed during 1959-63 & 347 & $3610 \cdot 3$ & $1341 \cdot 8$ & $350 \cdot 4$ & $34 \cdot 4$ & $5336 \cdot 9$ \\
\hline First exposed during $\mathbf{1 9 6 4 - 8}$ & 429 & $3753 \cdot 6$ & $1045 \cdot 3$ & $236 \cdot 5$ & $11 \cdot 8$ & $5047 \cdot 2$ \\
\hline $\begin{array}{l}\text { Total } \\
\text { Men exposed for under } 1 \text { year* }\end{array}$ & 934 & $8867 \cdot 4$ & $3345 \cdot 1$ & $1181 \cdot 5$ & $231 \cdot 3$ & $13625 \cdot 2$ \\
\hline Total & 177 & $2765 \cdot 8$ & $677 \cdot 0$ & $208 \cdot 8$ & $122 \cdot 5$ & $3774 \cdot 1$ \\
\hline
\end{tabular}

*Figures for man-years at risk include the first year at risk of each man exposed for one year or more. 
quinquennial periods $1950-4 \ldots 1970-4$ to the manyears at risk for the same period; rates for 1975-6 only were applied to the years at risk for the period 1975-8 since, at the time of analysis, no more recent data were available. Regional and social class specific mortality rates were not available for the whole of the study period, and rates for England and Wales, applying to all social classes, were used.

The probability levels quoted in the report were calculated on the assumption that, under the null hypothesis of equal risks of death from a given cause in the population under study and in the standard population, the number of observed deaths would be an observation from a Poisson distribution with parameter equal to the number of expected deaths. Standardised mortality ratios (SMRs) were not calculated throughout, since in many cases the numbers of expected deaths were too small for these to be useful indicators of the level of risk but, for convenience, rounded SMRs are shown in the main table. In referring to these the considerable sampling variability of the SMRs given should not be overlooked.

\section{Results}

DEATHS BY CAUSE AND AGE

There were only 11 deaths (compared with $22 \cdot 1$ expected) in the group of 177 men with under one year's exposure, and for each cause of death (except suicides where only 0.5 deaths were expected) fewer deaths were observed than expected.

Table 2 Deaths by cause for men exposed for one year or more

\begin{tabular}{|c|c|c|c|}
\hline Cause of death (ICD code) & Observed & Expected & $S M R$ \\
\hline All causes (0-999) & 68 & $72 \cdot 4$ & 90 \\
\hline All non-violent causes except malignant neoplasms $(0-139,210-799)$ & $34 *$ & $47 \cdot 8$ & 70 \\
\hline Tuberculosis $(010-019)$ & 1 & NA & - \\
\hline All neoplasms (140-239) & 21 & $18 \cdot 9$ & 110 \\
\hline All malignant neoplasms $(140-209)$ & 21 & $18 \cdot 6$ & 110 \\
\hline Cancer of stomach (151) & $5 *$ & $1 \cdot 9$ & 250 \\
\hline Cancer of colon (153) & 2 & $1 \cdot 1$ & 180 \\
\hline Cancer of pancreas (157) & 1 & $0 \cdot 8$ & 120 \\
\hline Cancer of trachea, bronchus, and lung (162) & 9 & $7 \cdot 6$ & 120 \\
\hline Cancer of testis (186) & 1 & NA & - \\
\hline Cancer of bladder (188) & 1 & $0 \cdot 5$ & 200 \\
\hline Cancer of brain (191) & 2 & 0.7 & 290 \\
\hline Endocrine, nutritional, and metabolic diseases (240-279) & 1 & $0 \cdot 7$ & 140 \\
\hline Diabetes mellitus (250) & 1 & 0.5 & 200 \\
\hline Diseases of circulatory system (390-458) & 26 & $32 \cdot 8$ & 80 \\
\hline Ischaemic heart disease $(410-414)$ & 18 & $24 \cdot 1$ & 70 \\
\hline Cerebrovascular disease $(430-438)$ & 2 & $4 \cdot 9$ & 40 \\
\hline Accidents (800-949) & $9^{*}$ & $4 \cdot 2$ & 210 \\
\hline Suicides $(950-959)$ & 4 & $1 \cdot 8$ & 220 \\
\hline
\end{tabular}

*0.025 < p $<0.05$.

SMR = Standardised mortality ratio.

NA $=$ Not available

Table 3 Selected causes of death by age

\begin{tabular}{|c|c|c|c|c|c|c|c|c|}
\hline \multirow[t]{3}{*}{ Cause of death (ICD code) } & \multicolumn{8}{|c|}{ Age at death } \\
\hline & \multicolumn{2}{|c|}{$15-44$} & \multicolumn{2}{|c|}{$45-54$} & \multicolumn{2}{|c|}{$55-64$} & \multicolumn{2}{|c|}{$\geqslant 65$} \\
\hline & Obs & $\operatorname{Exp}$ & Obs & $\operatorname{Exp}$ & Obs & $\operatorname{Exp}$ & Obs & $\operatorname{Exp}$ \\
\hline All causes $(0-999)$ & 14 & $15 \cdot 2$ & 19 & $23 \cdot 0$ & 22 & $22 \cdot 4$ & 13 & $11 \cdot 8$ \\
\hline All non-violent causes except malignant & & & & & & & & \\
\hline neoplasms $(0-139,210-799)$ & $2 *$ & $8 \cdot 4$ & 9 & $15 \cdot 4$ & 13 & $15 \cdot 2$ & 10 & $8 \cdot 7$ \\
\hline All malignant neoplasms (140-209) & 6 & $3 \cdot 1$ & 7 & $6 \cdot 0$ & 6 & $6 \cdot \overline{5}$ & 2 & $3 \cdot 0$ \\
\hline Cancer of stomach (151) & 1 & $0 \cdot 2$ & 1 & 0.6 & $3 \dagger$ & $0 \cdot 7$ & $\mathbf{0}$ & $0 \cdot 4$ \\
\hline Cancer of colon (153) & 1 & 0.2 & 1 & 0.4 & 0 & $0 \cdot 4$ & 0 & $0 \cdot 2$ \\
\hline Cancer of trachea, bronchus, and lung (162) & $3+$ & 0.7 & 3 & $2 \cdot 5$ & 1 & $3 \cdot 1$ & 2 & $1 \cdot \overline{3}$ \\
\hline Cancer of brain (191) & 0 & $0 \cdot 2$ & 1 & $0 \cdot 2$ & 1 & $0 \cdot 1$ & 0 & $0 \cdot 0$ \\
\hline Circulatory disease $(390-458)$ & 2 & $5 \cdot 1$ & 7 & $11 \cdot 3$ & 9 & $11 \cdot 1$ & 8 & $5 \cdot 4$ \\
\hline Respiratory disease (460-519) & $\mathbf{0}$ & 0.9 & 1 & $1 \cdot 8$ & 4 & $2 \cdot 5$ & 1 & 1.9 \\
\hline Bronchitis (490-491) & 0 & $0 \cdot 2$ & 1 & $0 \cdot 8$ & 3 & $1 \cdot 4$ & 1 & 0.9 \\
\hline Accidents (800-949) & 4 & $2 \cdot 6$ & 1 & $1 \cdot 0$ & 3 & 0.5 & 1 & $0 \cdot 1$ \\
\hline Suicides (950-959) & 2 & $1 \cdot 0$ & 1 & 0.5 & 1 & $0 \cdot 2$ & 0 & $0 \cdot 0$ \\
\hline
\end{tabular}

*0.005 < p < 0.01.

$\left.t_{0.025}<\mathrm{p}\right\}<0.05$. 
Table 2 shows the causes of death of men who were exposed to acrylonitrile for at least one year; each cause for which at least one death was observed is included and the numbers of observed deaths, expected deaths, and SMRs are shown. Slightly more deaths from cancers were observed than expected (21 v 18.9); this excess arising mainly from cancers of the lung, stomach, colon, and brain. Excesses were also present for accidents and suicides; none of the accidents occurred at work. Fewer deaths were observed than expected for diseases of the circulatory and respiratory systems (although for bronchitis there was an excess) and these led to overall shortfalls of observed compared with expected deaths for all causes and for all non-violent causes-that is, excluding accidents and suicides - except cancer. For stomach cancer, accidents, and all non-violent causes other than cancer the differences between the numbers of observed and expected deaths were statistically significant $(p<0.05)$.

Table 3 shows observed and expected deaths by age for men with at least one year's exposure to acrylonitrile; only the main causes of death are included. For cancer of the stomach in the 55-64 year age group and cancer of the lung in the 15-44 year age group the three deaths observed were significantly more than the 0.7 expected $(p<0.05)$. The overall excess of bronchitis deaths was almost entirely concentrated in the 55-64 year age group, and no deaths from respiratory diseases and only two from circulatory diseases $(5 \cdot 1$ expected) occurred in the 15-44 year age group.

To test the hypothesis that the statistically significant excess of lung cancer in those aged 15-44 was associated with duration of exposure to acrylonitrile the duration of exposure of the three men aged 15-44 who died from lung cancer was compared with the duration of exposure of controls up to the appropriate case's date of death. Controls were chosen separately for each of the cases by selecting all the men born during the same year as the case who were still alive on the case's date of death; results are set out in table 4. For one of the cases the duration of exposure of $13 \cdot 1$ years was considerably greater than the mean exposure of 6.4 years of the controls, but the difference was only just significant $(p=0.05)$. For one other case the duration of exposure was about the same as the control group mean and for the third case it was shorter, but this difference was not statistically significant. The mean exposure of the three cases was 8.3 years and the mean exposure for all 96 controls was $7 \cdot 7$ years. The difference between these figures was not statistically significant.

DEATHS BY YEAR OF FIRST EXPOSURE

Table 5 shows observed and expected deaths for men with at least one year's exposure to acrylonitrile according to the period in which they were first

Table 4 Comparison of lung cancer cases with controls

\begin{tabular}{|c|c|c|c|c|}
\hline \multicolumn{2}{|l|}{ Lung cancer cases } & \multicolumn{3}{|l|}{ Controls } \\
\hline Age at death $(y r)$ & Duration of exposure $(y r)$ & No of controls & $\begin{array}{l}\text { Mean duration of } \\
\text { exposure }(y r)\end{array}$ & $\begin{array}{l}\text { Standard deviation of } \\
\text { duration of exposure }(y r)\end{array}$ \\
\hline $\begin{array}{l}42 \\
40 \\
42\end{array}$ & $\begin{array}{r}5 \cdot 1 \\
13 \cdot 1 \\
6 \cdot 6\end{array}$ & $\begin{array}{l}31 \\
37 \\
28\end{array}$ & $\begin{array}{r}10 \cdot 1 \\
6.4 \\
6.8\end{array}$ & $\begin{array}{l}5 \cdot 7 \\
3 \cdot 4 \\
3 \cdot 8\end{array}$ \\
\hline
\end{tabular}

Table 5 Selected causes of death by year of first exposure

\begin{tabular}{|c|c|c|c|c|c|c|}
\hline \multirow[t]{3}{*}{ Cause of death (ICD codes) } & \multicolumn{6}{|c|}{ Year of first exposure } \\
\hline & \multicolumn{2}{|c|}{$1950-8$} & \multicolumn{2}{|c|}{$1959-63$} & \multicolumn{2}{|c|}{$1964-8$} \\
\hline & Obs & $\operatorname{Exp}$ & Obs & $\operatorname{Exp}$ & Obs & $\operatorname{Exp}$ \\
\hline All causes (0-999) & 35 & $31 \cdot 6$ & 21 & $23 \cdot 2$ & 12 & $17 \cdot 5$ \\
\hline $\begin{array}{l}\text { All non-violent causes except malignant neoplasms } \\
(0-139,210-799)\end{array}$ & & $21 \cdot 7$ & 9 & 15.0 & $4^{*}$ & $11 \cdot 0$ \\
\hline All malignant neoplasms $(140-209)$ & 8 & $8 \cdot 3$ & 7 & 5.9 & 6 & $4 \cdot 4$ \\
\hline Cancer of stomach (151) & 3 & $1 \cdot 0$ & 0 & 0.6 & 2 & 0.4 \\
\hline Cancer of colon (153) & 0 & $0 \cdot 5$ & 2 & $0 \cdot 4$ & $\mathbf{0}$ & $0 \cdot 3$ \\
\hline Cancer of trachea, bronchus, and lung (162) & 4 & $3 \cdot 6$ & 2 & $2 \cdot 3$ & 3 & $1 \cdot 6$ \\
\hline Cancer of brain (191) & 1 & $0 \cdot 2$ & 0 & $0 \cdot 3$ & 1 & $0 \cdot 2$ \\
\hline Circulatory disease $(390-458)$ & 16 & $.14 \cdot 4$ & 6 & $10 \cdot 6$ & 4 & $7 \cdot 7$ \\
\hline Respiratory disease (460-519) & 4 & $3 \cdot 8$ & 2 & 1.9 & $\mathbf{0}$ & $1 \cdot 3$ \\
\hline Bronchitis (490-491) & 4 & 1.9 & 1 & $0 \cdot 8$ & 0 & $0 \cdot 5$ \\
\hline Accidents (800-949) & 5 & $1 \cdot 1$ & 2 & $1 \cdot 6$ & 2 & $1 \cdot 5$ \\
\hline Suicides (950-959) & 1 & $0 \cdot 5$ & 3 & 0.7 & 0 & $0 \cdot 6$ \\
\hline
\end{tabular}

$* 0.01<\mathrm{p}<0.025$. 
Table 6 Selected causes of death by duration from first exposure

\begin{tabular}{|c|c|c|c|c|c|c|}
\hline \multirow[t]{3}{*}{ Cause of death (ICD code) } & \multicolumn{6}{|c|}{ Duration from first exposure $(y r)$} \\
\hline & \multicolumn{2}{|l|}{$1-9$} & \multicolumn{2}{|c|}{$10-15$} & \multicolumn{2}{|l|}{$>15$} \\
\hline & Obs & Exp & Obs & $\operatorname{Exp}$ & Obs & $\operatorname{Exp}$ \\
\hline All causes $(0-999)$ & 18 & $27 \cdot 3$ & 22 & $22 \cdot 7$ & 28 & $22 \cdot 2$ \\
\hline $\begin{array}{l}\text { All n n-violent causes except malignant neoplasms } \\
(0-139,210-799)\end{array}$ & 5 & $17 \cdot 0$ & 10 & $15 \cdot 1$ & 19 & $15 \cdot 6$ \\
\hline All malignant neoplasms $(140-209)$ & 8 & 6.6 & 8 & $6 \cdot 0$ & 5 & 5.9 \\
\hline Cancer of stomach (151) & 2 & 0.7 & 1 & 0.6 & 2 & 0.6 \\
\hline Cancer of colon (153) & 1 & $0 \cdot 4$ & 1 & $0 \cdot 4$ & 0 & 0.4 \\
\hline Cancer of trachea, bronchus, and lung (162) & 3 & 2.5 & 4 & 2.5 & 2 & 2.5 \\
\hline Cancer of brain (191) & 0 & 0.3 & 1 & $0 \cdot 2$ & 1 & $0 \cdot 1$ \\
\hline Circulatory diseases $(390-458)$ & 4 & $11 \cdot 3$ & 7 & 10.9 & 15 & 10.6 \\
\hline Respiratory diseases $(460-519)$ & 1 & 2.4 & 2 & $2 \cdot 1$ & 3 & 2.6 \\
\hline Bronchitis $(490-491)$ & 1 & $1 \cdot 0$ & 2 & $1 \cdot 0$ & 2 & $1 \cdot 2$ \\
\hline Accidents (800-949) & 3 & $2 \cdot 6$ & 3 & $1 \cdot 1$ & 3 & 0.5 \\
\hline Suicides $(950-959)$ & 2 & $1 \cdot 1$ & 1 & 0.5 & 1 & $0 \cdot 2$ \\
\hline
\end{tabular}

exposed; the number of men first exposed during each period is also shown. The figures indicate that whereas the ratio of observed to expected deaths was fairly constant in each group for all cancers, for other non-violent causes the ratio was about 1 in the 1950-8 group, lower than this in the 1959-63 group, and lower still in the 1964-8 group. In the 1964-8 group the four deaths observed were significantly fewer than the 11.0 expected $(p<0.025)$.

Table 6 shows the main causes of death analysed according to the period between first exposure and death; in allocating deaths to cells of the table the period between first exposure and death was calculated to the nearest day. An increasing excess of observed over expected deaths was found, as the period between first exposure and death increased, for all causes, all non-violent causes except malignant neoplasms, cancer of the brain, circulatory diseases, respiratory diseases, accidents, and suicides. Comparison of the ratios of observed to expected deaths in the 1-9 years and over 15 years' categories, however, showed statistically significant differences for all causes, all non-violent causes except malignant neoplasms, and circulatory diseases only ( $p<0.05)$. For all cancers and cancers of the lung, stomach, and colon no trend was evident.

\section{EXPOSURE DATA}

No data concerning measured levels of exposure to acrylonitrile were available for the period covered by this report, although in recent years environmental monitoring of the affected work areas has been introduced. Little can therefore be said about the levels of exposure experienced by the population studied, although these have always been limited to some degree because of the acute toxic effects of acrylonitrile. In three of the factories included in the study the nature of the processes carried out was such that some exposure to styrene and butadiene, as well as to acrylonitrile, would have occurred.

\section{Discussion}

\section{LIMITATIONS OF THE STUDY}

The method of analysis chosen was greatly influenced by the shortness of the follow-up period and the resulting small number of deaths expected in the study population. The commonly used division, between men with less than one year's exposure and those with more than this, was made to separate the group with no significant exposure to acrylonitrile from the rest. Apart from a special exercise on the duration of exposure of the three men aged under 45 who died from lung cancer, however, no further analysis of the results by duration of exposure was made. Although such an analysis might be carried out after a longer follow-up period to investigate dose/response, insufficient data were available at this stage to make this useful.

The familiar problems of choosing a suitable standard population to provide rates for calculating numbers of expected deaths have been widely discussed. A report ${ }^{6}$ on mortality in the rubber industry gave figures showing how the distribution of a study population by region, social class, and employment status could affect the numbers of deaths to be expected from particular causes. The use in the present study of mortality rates for the total male population of England and Wales may have led to biases in the numbers of expected deaths, and the results should be interpreted bearing in mind the following points.

The most relevant differences between the study population and the total male population of England and Wales arose from discrepancies between the regional, social class, and employment status 
distributions of the two groups. Mortality rates vary between the countries and regions of the United Kingdom, which means that the expected deaths calculated for individual factories may have been slightly distorted, either upwards or downwards. The overall effect, however, should have been small, since the population was fairly evenly distributed between areas with higher mortality rates for all causes than England and Wales $(47 \%$ in factories located in Wales and Scotland) and areas with the same or lower mortality rates than England and Wales $(53 \%$ in Northern Ireland and the East Midlands and south-east regions of England). For cancers, only Scotland has a mortality rate higher than England and Wales. For most of the study population mortality rates for social class IV (partly skilled occupations) would have been most appropriate if social class specific rates had been used. Figures published by OPCS? show that mortality rates for this group are higher than those for the total population, so not allowing for social class in this study led to a downward bias in the figures calculated for expected deaths for both cancer and non-cancer causes. For non-cancer causes an opposite bias to the social class effect was caused by the familiar "healthy-worker" selection effect which has been discussed, for example, by Fox and Collier. ${ }^{8}$ The study population consisted, by definition, of men who were in jobs at some time during the study period, whereas the standard population included the unemployed, the retired, and those unable to work because of sickness, all groups with generally higher mortality rates than the employed. This effect was most pronounced for men who entered the study population most recently. For those who worked during the earlier years the effect was not so important, since in the following years they had grown, as a group, to resemble more closely the general population. For all cancers and cancers of specific sites no variation of this type between the earlier and later years was apparent.

No objective data on the levels of exposure to acrylonitrile experienced by the population in the past were available, although levels are currently monitored. An attempt was made to estimate historical levels in the six plants covered by the study, but the only available methods of estimation were so subjective that little of value resulted from this exercise.

In view of the known association, information on smoking habit would have been particularly useful in interpreting the findings on lung cancer, but as would be expected for men working in the industry some time in the past, no such details were available. No overall excesses of circulatory and respiratory diseases, which are also known to be associated with smoking, were found and, although an excess of deaths from bronchitis was present, this was not statistically significant. Since other factors are also relevant for these diseases, however, and the latent periods are different from that for lung cancer, these results do not have a direct bearing on the assessment of a risk of lung cancer. Nevertheless, they do not indicate that the study population had greatly above average smoking habits.

\section{INTERPRETATION OF RESULTS}

The numbers of observed and expected deaths in the population with at least one year's exposure were not large enough to attribute statistical significance to all the excesses and shortfalls found. It seemed fairly clear that the low SMR of 70 for all non-violent causes other than cancer was due, at least in part, to the healthy-worker selection effect. This interpretation was reinforced by the fact that the mortality for cohorts defined by year of first exposure followed a typical healthy-worker pattern. For men first exposed during the period 1950-8 the numbers of deaths observed and expected from this group of causes were roughly equal, whereas for those first exposed more recently there was an increasing shortfall of observed compared with expected deaths. By contrast with this pattern, there were more deaths observed than expected from cancer (SMR = 110), and the balance seemed to be independent of the date of first exposure. Either no healthy-worker selection effect was present for cancers or such an effect was present but had been cancelled out by other factors working in the opposite direction. When allowance is made for differing methods of dealing with those with less than one year's exposure, comparison of results between this study and a study9 of men exposed to vinyl chloride monomer during the period 1940-74 showed that, although the SMRs for all cancers and all non-violent causes other than cancer were almost identical, the SMR for lung cancer in this study was higher, although the difference was not statistically significant. It should become increasingly valuable to pursue this comparison in the future when the follow-up period in both studies is longer. The two study populations consisted of men, probably with similar life styles, carrying out similar types of jobs in the chemical industry, and the single major difference between the populations was that they were exposed to different chemicals. In both studies England and Wales mortality rates were used for calculating the numbers of expected deaths.

Statistically significant excesses of deaths from stomach cancer were found overall and for those aged 55-64. All five men in the study population who died from stomach cancer worked in factories in Wales, however, where the mortality rate from 
stomach cancer during the period covered by the study was well above the England and Wales average. This suggests that the expected number of deaths calculated using England and Wales rates was an underestimate of the true figure and that the stomach cancer excesses may have been due to regional, rather than occupational, factors.

A statistically significant excess of deaths from lung cancer was found in those aged 15-44. Although the number of deaths observed was only three, the excess was of particular interest in that it occurred in relatively young men. A comparison between the duration of exposure of the three cases of lung cancer and the exposure of controls matched by year of birth showed no consistent tendency for the cases to have had longer exposure than the controls. This excess of deaths from lung cancer in young men cannot therefore be positively associated with acrylonitrile exposure, especially in the absence of information about the smoking habits of the men concerned, but it is a potential concern and will be investigated further when a longer follow-up period has elapsed.

The analysis of deaths by the length of time between first exposure and death gave no indication that excesses of stomach or lung cancer were appearing after a latency period of 10 or 15 years, although the numbers were too small to make this result conclusive.

\section{Conclusion}

The results of the present study are not conclusive, and re-analysis of the data after a longer follow-up period will be necessary. They neither add to nor detract from existing suspicions that acrylonitrile is a human carcinogen but, taken together with evidence from other studies, indicate the necessity for the continuing surveillance of the exposed population in the United Kingdom.
We gratefully acknowledge the efforts of individual companies in extracting information for the survey from their records and of the national registers in tracing the population. Administration and analysis of the survey was carried out by staff of HSE's medical statistics survey unit and the computer program used was written to a joint OPCS/HSE specification by Miss $\mathbf{P}$ Dyer of the computer division of OPCS. Early drafts of the report were widely discussed, and we are grateful for the valuable comments made by Sir Richard Doll of Oxford University, Dr R D Jones of the HSE, and several others.

\section{References}

${ }^{1}$ O'Berg MT. Epidemiologic study of workers exposed to acrylonitrile. J Occup Med 1980;22:245-52.

${ }^{2}$ Quast JF, Wade CE, Humiston CG, et al. A two-year toxicity and oncogenicity study with acrylonitrile incorporated in the drinking water of rats. Midland, Michigan: Dow Chemical Co,Toxicology Research Laboratory, 1980. (Report to the Chemical Manufacturers Association.)

${ }^{3}$ Maltoni C, Giliberti A, Di Maio V. Carcinogenicity bioassays on rats in acrylonitrile administered by inhalation and by ingestion. Med Lav 1977;68:401-11.

${ }^{4}$ Kiesselbach N, Korallus U, Lange HJ, Neiss A, Zwingers T. Acrylonitrile-epidemiological study-Bayer 1977. Zentralblatt für Arbeitsmedizin 1979;10:257-9.

${ }^{5}$ Thiess AM. Mortality study on skilled chemical workers employed in various production plants with exposure also to acrylonitrile. Zentralblatt für Arbeitsmedizin $1980 ; 30$, suppl 7:259-67.

6 Health and Safety Executive. Mortality in the British rubber industries. London: HMSO, 1980.

7 Office of Population Censuses and Surveys. Occupational mortality (decennial supplement) 1970-72. London: HMSO, 1978.

${ }^{8}$ Fox AJ, Collier PF. Low mortality rates in industrial cohort studies due to selection for work and survival in the industry. Br J Prev Soc Med 1976;30:225-30.

${ }^{9}$ Fox AJ, Collier PF. Mortality experience of workers exposed to vinyl chloride monomer in the manufacture of polyvinyl chloride in Great Britain. $\mathrm{Br} J$ Ind Med 1977;34:1-10. 